\title{
Diagnostic, Therapeutic and Evolutionary Characteristics of Nasopharyngeal Cancer in Morocco
}

Elamin Marnouche ${ }^{1 *}$, Mohammed Elmarjany ${ }^{1}$, Rachid Razine ${ }^{2}$, Abdelhak Maghous ${ }^{3}$, Issam Lalya ${ }^{1}$, Khalid Andaloussi $^{1}$, Amine Bazine ${ }^{1}$, Noha $^{2}$ Zaghba' $^{1}$, Khalid Hadadi ${ }^{1}$, Hassan Sifat ${ }^{1}$ and Hamid Mansouri' ${ }^{1}$

${ }^{1}$ Department of Radiotherapy, Mohamed V Military Hospital, Rabat, Morocco

${ }^{2}$ Department of Public Health, Laboratory of Biostatics, Clinical Research and Epidemiology, School of Medicine and Pharmacy of Rabat, Rabat, Morocco

${ }^{3}$ National Institute of Oncology, Rabat, Morocco

\begin{abstract}
Background: Nasopharyngeal carcinoma (NPC) is a radiosensitive and radio curable cancer, the radiation therapy (RT) is the mainstay of treatment with significant improvement in survival of patients. The aim of this study was to report the experience of Military Hospital Mohamed V in the management of NPC and their results.

Materials and methods: 83 no metastatic NPC patients managed at the radiotherapy department of Military Hospital Mohammed V of Rabat in Morocco, between January 2005 and December 2009, were included for investigation of their demographic, histological, therapeutic and follow-up characteristics. Statistical analysis of the data was carried out by the SPSS for Windows.

Results: The mean age was $44.5 \pm 12.5$ years with sex ratio 4:1. At diagnosis, rhinologic symptoms represented the most common clinical presentation, reported by $56(67,5 \%)$ patients. Almost ninety percent $(n=74)$ of patients presented UCNT histology. Most of the patients (85.5\%) presented a locally advanced disease; stage III and IV. Therefore, forty patients $(48.2 \%)$ were treated by concurrent chemoradiotherapy and 35 patients $(42.2 \%)$ received induction chemotherapy. With a mean follow up of $70 \pm 32$ months, twenty nine patients $(34.9 \%)$ died, $6(7.2 \%)$ presented local or locoregional relapse. While $11(13.2 \%)$ patients presented distant recurrences. The five years overall survival (OS) was $68 \%$ ranging from $91 \%$ for both stage I and II, $79.3 \%$ for stage III to $40 \%$ for stage IV. The five years disease free survival (DFS) was $81.1 \%$, whereas distant failure free survival (DFFS) was $84.1 \%$. In multivariate analysis, the disease stage according to the seventh edition of the AJCC system was an independent prognostic factor.
\end{abstract}

Conclusion: Our outcomes in NPC are similar to the literature. Patients' survival is directly impacted by the disease staging which is the most important prognostic factor. We hope to improve these results with the recent acquisition of volumetric-modulated arc therapy machines.

Keywords: Nasopharyngeal carcinoma; Radiotherapy; Concomitant radio-chemotherapy

Abbreviations: NPC: Nasopharyngeal Carcinoma; OS: Overall Survival; DFS: Disease Free Survival; DFFD: Distant Failure Free Survival; AJCC: American Joint Committee on Cancer Staging System; TNM: Tumor Node Metastasis; RT: Radiation Therapy; IMRT: Intensity Modulated Radiotherapy; CT: Computed Tomography; MRI: Magnetic Resonance Imaging; 5FU: 5 Fluoro Uracil; WHO: World Health Organization; IQR: Interquartile Range; EBV: Epstein Barr Virus; L-FFR: Local Failure-Free Rate; UCNT: Undifferentiated Carcinoma of Nasopharyngeal Type.

\section{Background}

Nasopharyngeal carcinoma (NPC) is a cancer arising from the nasopharynx epithelium. Within the boundaries of the nasopharynx, the tumor epicenter is frequently seen at the fossa of Rosenmuller, from where the tumor invades adjacent anatomical spaces or organs [1]. It differs from other head and neck squamous cell carcinomas in epidemiology, histology, natural history and response to treatment.

Nasopharyngeal carcinoma is an uncommon cancer in the most parts of the world and demonstrates a marked geographical variation. The age-adjusted incidence rate (per 100,000 people per year) among men ranges from 0.6 in the United States and Japan to 5.4 in Algeria, 5.8 in the Philippines, 11.0 in Singapore, 17.2 among Eskimos, Indians and Aleuts in Alaska to 17.8 and 26.9 in Hong Kong and Guangdong Province in Southern China, respectively [2-4]. In Morocco, there is a few data about incidence coming from several cities such as Casabalanca (3, 74 per $100,000 \mathrm{men} /$ year versus 0,88 per 100,000 women/year in 2004) [5] or rabat (3, 3 per 100,000 men per year versus 1,8 per 100,000 women per year in 2005) [6]. The male-to-female incidence ratio is $2: 1$ to $3: 1$. [7]. A bimodal age distribution is observed in low-risk populations (such as Europe and North America). The first peak incidence arises between 15 to 25 years of age, with the second peak at 50 to 59 years of age [8-10]. In high-risk populations (including Southeast Asia, North Africa, Eskimos) [11,12], the peak incidence occurs in the fourth and fifth decades of life [8].

Since it is a clinically occult site, patients may remain asymptomatic for a prolonged period. The majority of patients has a locally and/ or regionally advanced disease because of this asymptomatic period or, in some cases, due to a missed diagnosis $[13,14]$. Diagnosis of

*Corresponding author: Elamin Marnouche, Department of Radiotherapy Mohamed V Military Hospital, Rabat, Morocco, Tel: 212665096287; E-mail: elaminmarnouche@gmail.com

Received April 19, 2017; Accepted May 19, 2017; Published May 22, 2017

Citation: Marnouche E, Elmarjany M, Razine R, Maghous A, Lalya I, et al. (2017) Diagnostic, Therapeutic and Evolutionary Characteristics of Nasopharyngeal Cancer in Morocco. J Cancer Sci Ther 9: 439-444. doi: 10.4172/19485956.1000456

Copyright: (c) 2017 Marnouche E, et al. This is an open-access article distributed under the terms of the Creative Commons Attribution License, which permits unrestricted use, distribution, and reproduction in any medium, provided the original author and source are credited. 
nasopharyngeal carcinoma is made by biopsy of the primary tumor or Fine-needle aspiration of a suspicious neck mass. The staging workup is performed, as disease staging according to the American Joint Committee on Cancer staging system AJCC is considered as the most important prognostic factor.

The development of radiation therapy (RT) revolutionized the management of nasopharyngeal carcinoma with the advent of megavoltage machines; the review by Moss [15] in 1965 showing 25\% of patients alive at 5 years marked the first major breakthrough and established the role of RT as the primary modality of choice [16]. The adjunction of concurrent chemotherapy has more improved survival [17]. Recent development in RT techniques with Intensity-modulated radiotherapy (IMRT) further improved tumor coverage and organs at risk sparing.

The aim of this study was to report the experience of Military Hospital Mohamed V in the management of NPC.

\section{Methods}

This was a retrospective analytic study of 83 no metastatic NPC patients treated at the radiotherapy department of Military Hospital Mohammed V of Rabat in Morocco, between January 2005 and December 2009. Informed verbal consent was obtained from all patients to access and use their patient data. This study was submitted to and approved by research committee of military teaching hospital Mohamed V.

Patients were investigated by physical examination, fiberoptic examination, head and neck computed tomography CT, Magnetic resonance imaging MRI was not used currently, chest X-ray and abdominal ultrasound or thoracic and abdominal CT. Bone scan was performed if clinically indicated and for patients with locally advanced disease. The seventh edition of the AJCC system was used for disease staging.

All patients were treated by $3 \mathrm{D}$ radiotherapy technique using lateral opposing cervicofacial fields that encompassed the primary tumor and the upper neck nodes in one volume with a matching lower anterior cervical field for the lower cervical lymphatics in order to deliver a "prophylactic dose" $50 \mathrm{~Gy}, 2 \mathrm{~Gy} /$ fraction with a first lateral treatment fields reduction "spine off" at 40 Gy and electron therapy was used to complete dose in this area to respect spinal cord tolerance. Then, treatment fields were reduced again to reach 70 Gy in primary tumor and, if technically possible with photons X $6 \mathrm{MV}$, in pathologic cervical lymph nodes. If not, electron therapy was used to complete the dose in cervical lymphadenopathies. Regarding organs at risk, especially critical structures, we tried to respect tolerance's threshold. However, radiation technique capabilities and disease stage (mostly locally advanced disease) were the main limitations. All patients were well informed of radiation risk in term of late toxicities.

The radiation treatment was used alone or with concurrent chemotherapy based on weekly cisplatin. Induction chemotherapy was administered for patients with locally advanced disease and different regimens were used based on cisplatin, anthracycline and 5FU.

The patient's follow-up continued according to the following schedule: every 3 months for the first 2 years, every 6 months for the 3 th, 4th and 5th years and then annually. Physical examination especially head and neck was performed in every visit. CT scan and fiberoptic examination were performed periodically to evaluate the response, to detect relapse and to assess late effects.
Data was collected using a well-structured checklist containing the important study parameters. The record collection included the patient related data (age at diagnosis and gender). Data included also clinical presenting symptoms (rhinologic, otologic, neurologic and lymph node syndromes), duration of symptoms (months) and other clinical data such as TNM classification and stage of disease according to the AJCC seventh edition 2010 and the histological type according to the world health organization WHO classification 1978. The type, the modalities of primary treatment (radiotherapy, chemotherapy, both), the date and the sites of relapse (local, loco regional, distant metastases), the follow up data, the death date and the date of last follow-up visit were also recorded.

Statistical analysis of the data was carried out by the SPSS 20 for Windows (SPSS, Inc., Chicago, IL, USA). Qualitative variables were presented as number and percentages. Quantitative variables were presented as mean \pm standard deviation for variables with normal distribution and as median and interquartile range (IQR) for variables with skewed distributions. Khi2 test was used to compare qualitative variables. The survival rate was analyzed with the Kaplan-Meier method.

\section{Results}

Eighty three patients were treated in our department. Table 1 summarizes their clinical, para clinical, histological characteristics and treatment modalities.

The mean age was $44.5 \pm 12.5$ years with sex ratio $4: 1$. At diagnosis, the rhinologic symptoms represented the most common clinical presentation $(67,5 \%)$. Otologic symptoms and adenomegaly were present respectively in $50(60.2 \%), 44(53 \%)$ patients. The median symptoms duration before histologic diagnosis was 8.9 months [7-12]. According to the former WHO classification, almost ninety percent of patients presented UCNT histology.

Most of patients (85.5\%) presented a locally advanced disease (stage III and IV). Therefore, chemotherapy was usually administrated (concomitant or induction chemotherapy). Induction chemotherapy was delivered in $3.1 \pm 0.52$ cycles.

With a mean follow up of $70 \pm 32$ months, twenty nine patients (34.9\%) died, 6 (7.2\%) presented local or locoregional relapse. While 11 (13.2\%) patients presented distant recurrences, half of them occurred in bone. The mean duration of recurrence was $23.6 \pm 17.28$ months. Forty six (55.4\%) patients were healthy and $8(9.6 \%)$ patients were lost to follow up. We tried to contact all patients who were lost to follow-up by phone and by sending correspondence letter without response.

The five year overall survival (OS) was $68 \%$ ranging from $91 \%$ for both stage I and II, $79.3 \%$ for stage III to $40 \%$ for stage IV (Figures 1 and 2). The five year disease free survival (DFS) was $81.1 \%$ (Figure 3) whereas distant failure free survival (DFFS) was $84.1 \%$.

In univariate analysis shown in Tables 2 and 3, the TNM stage impacted significantly OS $(\mathrm{p}=0.002)$, DFS $(\mathrm{p}=0.001)$ and DFFS $(\mathrm{p}=0.002)$. T-category influenced significantly OS $(\mathrm{p}=0.012)$ and DFS $(p=0.022)$ whereas $\mathrm{N}$ - category influenced significantly both DFS $(\mathrm{p}=0.019)$ and DFFS $(\mathrm{p}=0.001)$. Induction chemotherapy as treatment modality was a significant factor for both DFS $(\mathrm{p}=0.001)$ and DFFS $(\mathrm{p}=0.018)$. Moreover, duration between induction chemotherapy and radiotherapy also influenced statistically DFS $(\mathrm{p}=0.028)$ and DFFS $(\mathrm{p}=0.04)$. For OS, TNM stage was an independent prognostic factor in multivariate analysis $(\mathrm{p}=0.002)$. However, Multivariate analysis was not 
Citation: Marnouche E, Elmarjany M, Razine R, Maghous A, Lalya I, et al. (2017) Diagnostic, Therapeutic and Evolutionary Characteristics of Nasopharyngeal Cancer in Morocco. J Cancer Sci Ther 9: 439-444. doi: 10.4172/1948-5956.1000456

performed for DFS and DFFS because of the relatively small number of events.

\begin{tabular}{|c|c|}
\hline Item & Results \\
\hline $\begin{array}{l}\text { Age }^{\circ} \\
\text { Gender \$ }\end{array}$ & $44.5 \pm 12.5$ \\
\hline Men & $96(83.1)$ \\
\hline $\begin{array}{c}\text { Women } \\
\text { Clinical review } \$\end{array}$ & $14(16.9)$ \\
\hline \multicolumn{2}{|l|}{ Lymph node syndromes \$ } \\
\hline Unilateral & $36(43.4)$ \\
\hline Bilateral & $8(9.6)$ \\
\hline Otologic syndrome $\$$ & $50(60.2)$ \\
\hline Neurologic Syndrome \$ & $16(19.3)$ \\
\hline Rhinologic syndrome \$ & $56(67.5)$ \\
\hline Time between initial symptoms and diagnosis* (months) & $8.9[7-12]$ \\
\hline \multicolumn{2}{|l|}{ Histology \$ } \\
\hline Type (I) & 0 \\
\hline Type (II) & $9(10.8)$ \\
\hline $\begin{array}{c}\text { Type (III) } \\
\text { Para clinical review \$ }\end{array}$ & $74(89.2)$ \\
\hline Cervicofacial CT & $83(100)$ \\
\hline Nasopharyngeal MRI & $7(8.4)$ \\
\hline Chest $X$ ray & $78(94)$ \\
\hline Abdominal ultrasound & $74(89.2)$ \\
\hline Thoracic and abdominal CT & $11(13.3)$ \\
\hline Bone scan & $55(66.3)$ \\
\hline \multicolumn{2}{|l|}{ Stage \$ } \\
\hline 1 & $7(8.4)$ \\
\hline II & $5(6)$ \\
\hline III & $38(45.8)$ \\
\hline IV & $33(39.7)$ \\
\hline \multicolumn{2}{|l|}{ Treatment modalities $\$$} \\
\hline Radiotherapy alone & $7(8.4)$ \\
\hline Concurrent Chemoradiotherapy & $40(48.2)$ \\
\hline $\begin{array}{l}\text { Induction chemotherapy followed by Concurrent chemoradiotherapy } \\
\text { Induction chemotherapy regimen } \\
\text { Cisplatin, anthracycline, 5FU } \\
\text { Cisplatin, anthracycline } \\
\text { Cisplatin, 5FU }\end{array}$ & $\begin{array}{l}35(42.2) \\
7(20) \\
23(65.7) \\
5(14.3)\end{array}$ \\
\hline $\begin{array}{l}\text { Duration between induction chemotherapy and radiotherapy } \\
\text { (days) }\end{array}$ & $\begin{array}{l}43.24 \pm \\
20.31\end{array}$ \\
\hline \multicolumn{2}{|l|}{$\begin{array}{l}\text { ¿Quantitative variable presented as mean } \pm \text { standard deviation } \\
\text { * Quantitative variable presented as median and interquartile range } \\
\$ \text { Qualitative variable presented as number }(n) \text { and percentage }(\%): n(\%) \text {. }\end{array}$} \\
\hline
\end{tabular}

Table 1: Clinical, para-clinical, histological, therapeutic characteristics of patients.

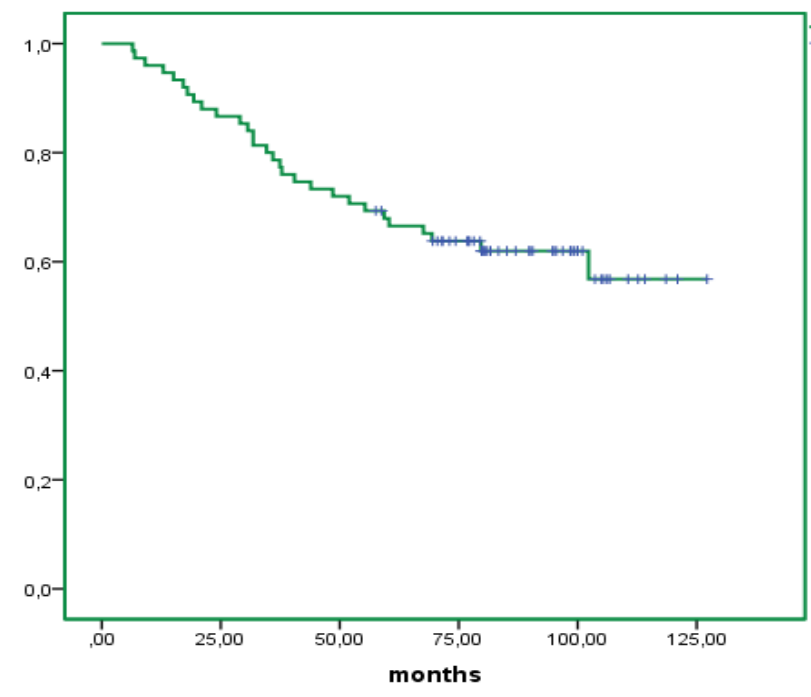

Figure 1: Overall survival.

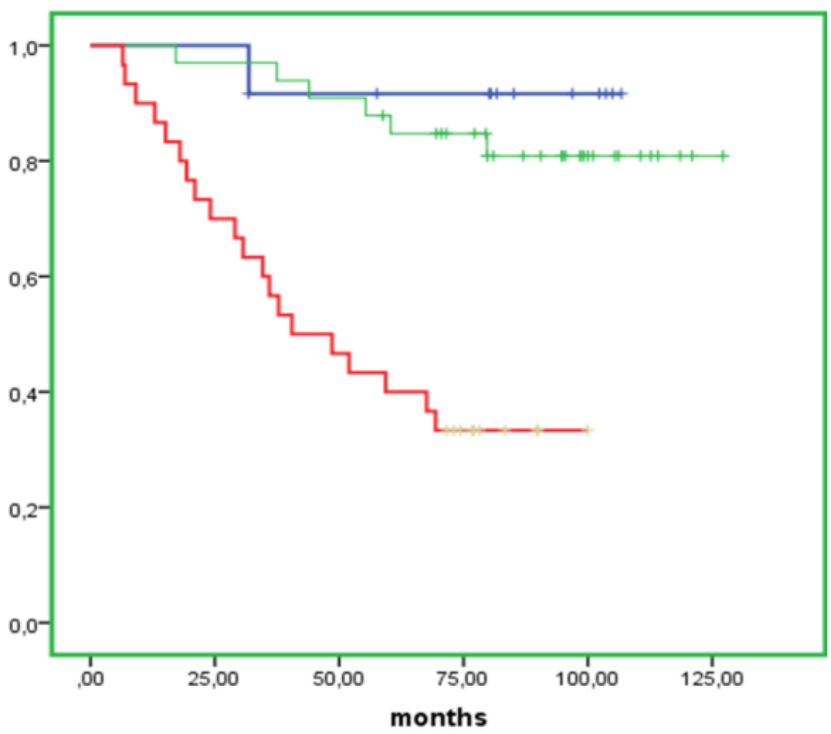

Figure 2: Overall survival reported by stage.

\begin{tabular}{|c|c|c|c|c|c|c|c|c|c|}
\hline & & os & & & DFS & & & DFFS & \\
\hline & $\mathrm{p}$ & OR & $95 \%$ IC & $\mathrm{p}$ & OR & $95 \%$ IC & $\mathrm{p}$ & OR & $95 \%$ IC \\
\hline TNM stage & 0.002 & 0.38 & $0.2-0.70$ & 0.001 & 5.79 & $2.17-15.41$ & 0.002 & 4.64 & $1.8-12$ \\
\hline T category & 0.012 & 0.56 & $0.36-0.88$ & 0.022 & 2.10 & $1.11-3.98$ & 0.34 & - & - \\
\hline $\mathrm{N}$ category & 0.24 & - & - & 0.019 & 2.87 & $1.2-7$ & 0.001 & 15 & $3.09-72$ \\
\hline Parapharyngeal space involvement & 0.054 & - & - & 0.18 & - & - & 0.26 & - & - \\
\hline Gender & 0.98 & - & - & 0.83 & - & - & 0.76 & - & - \\
\hline Histology & 0.55 & - & - & 0.99 & - & - & 0.99 & - & - \\
\hline Induction chemotherapy & 0.06 & - & - & 0.001 & 13.9 & $2.8-69.4$ & 0.018 & 5.6 & $1.34-23.4$ \\
\hline Induction chemotherapy regimen & 0.9 & - & - & 0.69 & - & - & 0.7 & - & - \\
\hline Time between induction chemotherapy and radiotherapy & 0.054 & - & - & 0.028 & 1.04 & $1.04-1.07$ & 0.04 & 1.04 & $1.02-1.07$ \\
\hline Time between initial symptoms and diagnosis & 0.12 & - & - & 0.81 & - & - & 0.4 & - & - \\
\hline
\end{tabular}

Table 2: Univariate analysis for factors influencing overall, disease free, distant failure free survival. 


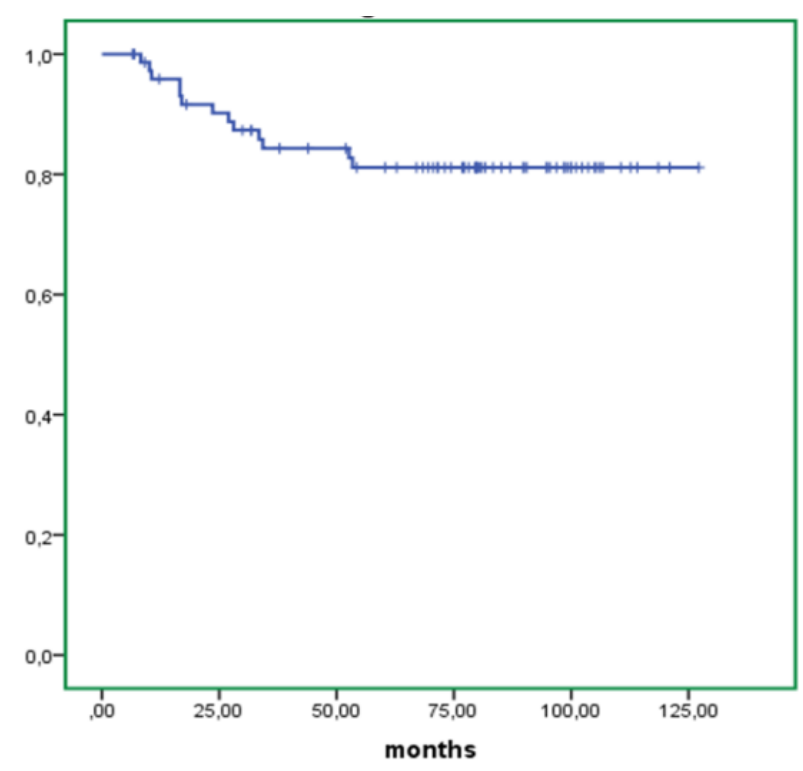

Figure 3: Disease free survival.

\begin{tabular}{|c|c|}
\hline Late toxicities & Frequency (\%) \\
\hline Trismus & $39.4(\mathrm{n}=33)$ \\
\hline Hyposialia (grade3)* & $38.5(\mathrm{n}=32)$ \\
Cervical fibrosis & $19.3(\mathrm{n}=16)$ \\
Otologic disorders & $61.5(\mathrm{n}=48)$ \\
\hline *According to CTCAE v3.0 & \\
\hline
\end{tabular}

Table 3: Proportion of late toxicities.

Five women (17.2\%) died versus $24(82.8 \%)$ men. Forty percent of women who died were under 40 years of age versus $60 \%$ but it was not statistically significant.

\section{Discussion}

Chemoradiotherapy is the mainstay of NPC treatment. It improved significantly survival rates which decreased with disease stage. We found that the five years overall survival was $68 \%$, ranging from $91 \%$ for stage I and II to $40 \%$ for stage IV. The TNM stage remained the most important prognostic factor.

The five years OS was $68 \%$; $91 \%$ for both stage I and II, $79,3 \%$ and $40 \%$ for stage III and stage IV respectively; whereas Five-years OS rates from series ranged from $36 \%$ to $58 \%$ [18-23]. Lee et al. found in a retrospective study including 2687 patients, a five years OS rate of $75 \%$ with $75 \%$ and $58 \%$ for stage III and IV respectively [16]. In the same study, they reported DFFS of $81 \%$ versus $84.1 \%$ in our institution.

The TNM staging is the most important prognostic factor. In general, advanced T-category is associated with worse local control and overall survival whereas advanced $\mathrm{N}$-category predicts an increased risk of distant metastasis and a worse survival. In multivariate analysis, TNM stage was an independent prognostic factor $(\mathrm{p}=0.002)$ impacting overall survival. In univariate analysis, T-category influenced significantly OS $(\mathrm{p}=0.012)$ and DFS $(\mathrm{p}=0.022)$ whereas $\mathrm{N}$ - category influenced significantly both of DFS ( $\mathrm{p}=0.019)$ and DFFS $(\mathrm{p}=0.001)$.

In addition to $\mathrm{T}$ and $\mathrm{N}$ categories, pre- and post-therapy Epstein Barr virus (EBV) DNA levels have a prognostic significance: higher levels confer a worse prognosis, stage for stage [24-27]. Five-years survival rates according to tumor node metastasis (TNM) stage grouping and pretherapy EBV DNA levels from one case series are as following: Stage I, II disease, low DNA (<4000 copies/mL)-91\%, Stage I, II disease, high DNA ( $\geq 4000$ copies/mL)-64\%, Stage III, IV disease, low DNA-66\%, Stage III, IV disease, high DNA-54\% [26]. As the research of EBV DNA is not a standard of a work up in the NPC, we did not perform EBV DNA levels in the routine practice.

Parapharyngeal space extension may be associated to distant metastasis. Cheng et al. [28] found parapharyngeal space extension to be the key factor in distant metastasis even in N1 and N2 NPC. However, Teo et al. [29] did not find parapharyngeal space involvement to be an independent significant prognostic factor in a study of 903 patients. In this study, we did not find that the parapharyngeal space involvement affects the occurrence of distant metastasis $(p=0,26)$. These contradictory findings may be attributed to the varying definitions of parapharyngeal space and the incidence in the different series.

Another prognostic factor to consider is the gross volume of the primary tumor (GTV-P). Although it is highly correlated to T-stage, considerable variability in tumor volume exists within the same T-stage, and evidence increasingly suggests that tumor volume as an independent significant factor can better predict prognosis than T-category as specified by AJCC [29-32]. In a study of 308 patients staged with MRI, Sze et al. [32,33] showed that those with GTV-P of $<15 \mathrm{~cm}^{3}$ had significantly higher L-FFR than those with a value of $\geq 15$ $\mathrm{cm}^{3}$ (97\% vs. $82 \%$ at 3 years; $\left.\mathrm{p}<0.01\right)$. Multivariate analysis confirmed GTV-P to be a strongly significant factor independent of T-category by the 1997 fifth edition of the AJCC; the risk of local failure increased by $1 \%$ for every $1-\mathrm{cm}^{3}$ increase in volume.

Most series found significantly better prognosis for females and younger patients [34]; in this study, five women (17.2\%) died versus 24 $(82.8 \%)$ men. Forty percent of women who died were under 40 years of age versus $60 \%$ but it was not statistically significant.

Depending on the degree of differentiation, nasopharyngeal carcinoma was categorized into three pathological subtypes, on the basis of WHO criteria, as follows: (I) squamous cell carcinoma, (II) no keratinizing carcinoma, and (III) undifferentiated carcinoma (UCNT: undifferentiated carcinoma of nasopharyngeal type) [35]. In the current World Health Organization (WHO) pathologic classification, [36] released in 2005, types II and III were combined into a single category of non-keratinizing carcinoma. A third category, the basaloid squamous carcinoma, was added. Of note, the former WHO classification remains quite commonly used. Although not all studies found histology to be an independent prognostic factor, $[37,38]$ many found no keratinizing and undifferentiated carcinomas to be more radiosensitive and offer better prognosis than keratinizing squamous cell carcinoma [39-41]. We found that histology did not affect overall survival $(\mathrm{p}=0.55)$.

The role of induction chemotherapy followed by either RT alone or concurrent chemoradiotherapy is unclear. The MAC-NPC metaanalysis included data from 1039 patients included in six trials [17]. There was a statistically significant improvement in progression free survival (47 versus 39 percent at 5 years, HR $0.81,95 \%$ CI 0.69 $0.95)$. However, the difference in overall survival was not statistically significant (57 versus 55 percent at 5 years, HR 0.96, 95\% CI 0.80-1.16). In a multicenter phase III trial conducted by Sun Yat-sen University at 10 centers in China, 480 patients with stage III-IVB, node-positive disease were randomly assigned to sequential chemotherapy with three cycles of docetaxel, cisplatin, and fluorouracil (TPF) followed by concurrent cisplatin plus RT, or to concurrent cisplatin plus RT 
Citation: Marnouche E, Elmarjany M, Razine R, Maghous A, Lalya I, et al. (2017) Diagnostic, Therapeutic and Evolutionary Characteristics of Nasopharyngeal Cancer in Morocco. J Cancer Sci Ther 9: 439-444. doi: 10.4172/1948-5956.1000456

alone without adjuvant chemotherapy [42]; Failure-free survival at three years was significantly better in those receiving induction TPF compared with concurrent chemoradiotherapy alone (80 versus 72 percent, HR $0.68,95 \%$ CI $0.48-0.97)$. The three-year overall survival rate was also significantly better in those receiving induction TPF (92 versus 86 percent, HR 0.59, 95\% CI 0.36-0.95). Distant metastases were significantly reduced, and local regional failure was lower, although not significantly, in the induction arm [42]. We found that induction chemotherapy influenced DFS $(p=0.001)$ and DFFS (0.018) in univariate analysis. Moreover, time between induction chemotherapy and radiotherapy also influenced statistically DFS $(\mathrm{p}=0.028)$ and DFFS $(p=0.04)$. In theory, induction chemotherapy may control micrometastases earlier and facilitate RT planning by downstaging locally advanced tumors, especially for large T4 lesions, advanced nodal disease, or when delivery of a full course RT is challenging due to close proximity to critical structures [43]. Therefore, it seems reasonable that time between induction chemotherapy and RT could have an effect on survival. Induction chemotherapy was typically given 3 weeks prior to the initiation of RT [44].

Intensity-modulated radiotherapy (IMRT) has supplanted conventional radiotherapy in the treatment of NPC in an increasing number of institutions throughout the world. In centers where modern radiation technology is available, IMRT is the preferred method. Briefly, this technique caters for delivery of tumoricidal doses to gross tumor and subclinical disease, while minimizing doses to adjacent normal tissues. The recent improvement in disease control and survival in patients with nasopharyngeal carcinoma is partly attributable to IMRT [1]. A review of 1593 patients who were treated at a single institution with progressive radiotherapy techniques (2D radio therapy, 3D radiotherapy, and IMRT) over two decades (1994 to 2010) also showed increased disease-specific and overall survival in individuals who received IMRT [45]. In a randomized study by Peng and colleagues, IMRT contributed to an absolute improvement in 5-years loco regional control of 7.7\% compared with conventional 2D radiotherapy. [46]

The relatively small number of patients was the main limitation of this study. However, we did this choice to have a sufficient follow-up time. A lack of reporting toxicities (grading) was also noted. Therefore more rigors will be needed and procedures will be established to correct this lack of reporting.

\section{Conclusion}

Our results in NPC management are similar to the literature. Patient's survival is directly impacted by the disease staging which is the most important prognostic factor. We hope to improve these results with the recent acquisition of volumetric-modulated arc therapy machines.

\section{Competing Interest}

The authors declare that they have no competing interests.

\section{Funding}

Special thanks are due to the Faculty of Medicine and Pharmacy of Rabat; the source(s) of funding for all authors

\section{Authors' Contribution}

E.M. and M.E, performed research and share the first position on article; E.M. R.R and A.M, analyzed data statistically; E.M. and A.M., collected the clinical data; K.A, A.B., I.L., K.H, H.S, N.Z and H.M, designed and coordinated research and drafted the manuscript. All authors read and approved the final manuscript.

\section{Acknowledgement}

All the authors are thankful for providing the necessary facilities for the preparation the manuscript.

\section{References}

1. Chua ML, Wee JT, Hui EP, Chan AT (2016) Nasopharyngeal carcinoma. Lancet 387: 1012-1024.

2. Lanier A, Bender T, Talbot M (1980) Nasopharyngeal carcinoma in Alaskan Eskimos Indians, and Aleuts: a review of cases and study of Epstein-Barr virus HLA, and environmental risk factors. Cancer 46: 2100-2106.

3. Parkin D, Muir C, Whelan S (1992) Cancer incidence in five continents. In Parkin D (eds) Epidemiology. IARC Scientific Publications, Lyon, France.

4. Curado M, Edwards $B$, Shin $H$ (2007) Cancer incidence in five continents. IARC Scientific Publications, Lyon, France.

5. Plan national de prevention et de contrôle du cancer (2004) analyse de la situation.

6. Registre des cancers de rabat (2005) incidence des cancers.

7. Ferlay J, Shin HR, Bray F (2010) Estimates of worldwide burden of cancer in 2008: GLOBOCAN 2008. Int J Cancer 127: 2893-2917.

8. Ferlay J, Shin H, Bray F (2008) Cancer incidence and mortality worldwide: IARC CancerBase No. 10. International Agency for Research on Cancer, Lyon, France.

9. Balakrishnan $U$ (1975) An additional younger-age peak for cancer of the nasopharynx. Int J Cancer 15: 651-657.

10. Singh W (1987) Nasopharyngeal carcinoma in Caucasian children. A 25-year study. J Laryngol Otol 101: 1248-1253.

11. Bhandare N, Antonelli PJ, Morris CG, Malayapa RS, Mendenhall WM (2007) Ototoxicity after radiotherapy for head and neck tumors. Int J Radiat Oncol Bio Phys 67: 469-479.

12. Bourhis J, Schwaab G (1999) Cancer du Nasopharynx (cavum). In: Elsevier (eds) Encylopédie Médico-chirurgicale.

13. Leong JL, Fong KW, Low WK (1999) Factors contributing to delayed diagnosis in nasopharyngeal carcinoma. J Laryngol Otol 113: 633.

14. Hsu MM, Tu SM (1983) Nasopharyngeal carcinoma in Taiwan. Clinical manifestations and results of therapy. Cancer 52: 362 .

15. Moss WT (1965) Therapeutic radiology (2nd ed). St Louis, CV Mosby, pp: 142-180

16. Lee AW, Sze WM, Au JS (2005) Treatment results for nasopharyngeal carcinoma in the modern era: the Hong Kong experience. Int J Radiat Oncol Biol Phys 61: 1107

17. Blanchard P, Lee A, Marguet S (2015) Chemotherapy and radiotherapy in nasopharyngeal carcinoma: an update of the MAC-NPC meta-analysis. Lancet Oncol 16: 645.

18. Chu AM, Flynn MB, Achino E (1984) Irradiation of nasopharyngeal carcinoma: correlations with treatment factors and stage. Int J Radiat Oncol Biol Phys 10: 2241-2249.

19. Hoppe RT, Goffinet DR, Bagshaw MA (1976) Carcinoma of the nasopharynx Eighteen years' experience with megavoltage radiation therapy. Cancer 37: 2605-2612.

20. Mesic JB, Fletcher GH, Goepfert H (1981) Megavoltage irradiation of epithelial tumors of the nasopharynx. Int J Radiat Oncol Biol Phys 7: 447-453.

21. Bailet JW, Mark RJ, Abemayor E (1992) Nasopharyngeal carcinoma: treatment results with primary radiation therapy. Laryngoscope 102: 965-972.

22. Wang C (1990) Carcinoma of the nasopharynx. In: Wang CC (ed) Radiation Therapy for Head and Neck Neoplasms: Indications, Techniques, and Results. Year Book Medical Publishers, Chicago, pp: 261-283.

23. Vikram B, Strong EW, Manolatos S (1984) Improved survival in carcinoma of the nasopharynx. Head Neck Surg 7: 123-128.

24. Geara FB, Sanguineti G, Tucker SL (1997) Carcinoma of the nasopharynx treated by radiotherapy alone: determinants of distant metastasis and survival. Radiother Oncol 43: 53.

25. e QT, Jones CD, Yau TK (2005) A comparison study of different PCR assays 
Citation: Marnouche E, Elmarjany M, Razine R, Maghous A, Lalya I, et al. (2017) Diagnostic, Therapeutic and Evolutionary Characteristics of Nasopharyngeal Cancer in Morocco. J Cancer Sci Ther 9: 439-444. doi: 10.4172/1948-5956.1000456

in measuring circulating plasma epstein-barr virus DNA levels in patients with nasopharyngeal carcinoma. Clin Cancer Res 11: 5700.

26. Lin JC, Wang WY, Chen KY (2004) Quantification of plasma Epstein-Barr virus DNA in patients with advanced nasopharyngeal carcinoma. N Engl J Med 350: 2461-2470

27. Leung SF, Zee B, Ma BB (2006) Plasma Epstein-Barr viral deoxyribonucleic acid quantitation complements tumor-node-metastasis staging prognostication in nasopharyngeal carcinoma. J Clin Oncol 24: 5414-5418.

28. Cheng SH, Tsai SY, Yen KL (2005) Prognostic significance of parapharyngeal space venous plexus and marrow involvement: potential landmarks of dissemination for stage I-III nasopharyngeal carcinoma. Int J Radiat Oncol Biol Phys 61: 456-465.

29. Teo P, Yu P, Lee WY (1996) Significant prognosticators after primary radiotherapy in 903 nondisseminated nasopharyngeal carcinoma evaluated by computer tomography. Int J Radiat Oncol Biol Phys 36: 291-304

30. Chua DT, Sham JS, Kwong DL (1997) Retropharyngeal lymphadenopathy in patients with nasopharyngeal carcinoma: a computed tomography-based study. Cancer 79: 869-877.

31. Chen MK, Chen TH, Liu JP (2004) Better prediction of prognosis for patients with nasopharyngeal carcinoma using primary tumor volume. Cancer 100: 2160-2166.

32. Sze WM, Lee AW, Yau TK (2004) Primary tumor volume of nasopharyngeal carcinoma: prognostic significance for local control. Int $\mathrm{J}$ Radiat Oncol Biol Phys 59: 21-27.

33. Chong VF, Zhou JY, Khoo JB (2005) Correlation between MR imaging-derived nasopharyngeal carcinoma tumor volume and TNM system. 64: 72-76.

34. Sham JS, Choy D (1990) Prognostic factors of nasopharyngeal carcinoma: a review of 759 patients. Br J Radiol 63: 51-58

35. Cammoun M, Ellouz R, Behi J, Attia RB (1978) Histological types of nasopharyngeal carcinoma in an intermediate risk area. IARC Sci Publ 20: 13-26.
36. Chan J, Bray F, McCarron P (2005) Nasopharyngeal carcinoma. In: Pathology and genetics of head and neck tumours. World Health Organization classification of tumours. IARC Press, Lyon, France, pp: 85-97.

37. Perez CA, Devineni VR, Marcial-Vega V (1992) Carcinoma of the nasopharynx factors affecting prognosis. Int J Radiat Oncol Biol Phys 23: 271-280.

38. Bohorquez $J$ (1976) Factors that modify the radio-response of cancer of the nasopharynx. AJR Am J Roentgenol 126: 863-876.

39. Chu AM, Flynn MB, Achino E (1984) Irradiation of nasopharyngeal carcinoma: correlations with treatment factors and stage. Int J Radiat Oncol Biol Phys 10: 2241-2249.

40. Applebaum EL, Mantravadi P, Haas R (1982) Lymphoepithelioma of the nasopharynx. Laryngoscope 92: 510-514.

41. Marks JE, Phillips JL, Menck HR (1998) The National Cancer Data Base report on the relationship of race and national origin to the histology of nasopharyngeal carcinoma. Cancer 83: 582-588.

42. Sun Y, Li WF, Chen NY (2016) Induction chemotherapy plus concurrent chemoradiotherapy versus concurrent chemoradiotherapy alone in locoregionally advanced nasopharyngeal carcinoma: a phase 3, multicentre, randomised controlled trial. Lancet Oncol 17: 1509-1520.

43. Tan WL, Tan EH, Lim DW (2016) Advances in systemic treatment for nasopharyngeal carcinoma. Chin Clin Oncol 5: 21.

44. Zhao L, Xu M, Jiang (2017) WInduction chemotherapy for the treatment of nonendemic locally advanced nasopharyngeal carcinoma. Oncotarget Adv Pub 8: 6763-6774.

45. Peng G, Wang T, Yang KY (2012) A prospective, randomized study comparing outcomes and toxicities of intensity-modulated radiotherapy vs. conventional two-dimensional radiotherapy for the treatment of nasopharyngeal carcinoma. Radiother Oncol 104: 286-293.

46. Lee AW, Ng WT, Chan LL (2014) Evolution of treatment fornasopharyngea cancer-success and setbackin the intensitymodulate radiotherapy era. Radiother Oncol 110: 377-384. 